\title{
Circadian variation of F.E.V. in shift workers
}

\author{
E. GUBERAN,' M. K. WILLIAMS, JOAN WALFORD, AND \\ MARGARET M. SMITH \\ London School of Hygiene and Tropical Medicine T.U.C. Centenary Institute of \\ Occupational Health, and the Medical Department, Electric Power Storage Co. Ltd., \\ Dagenham Dock, Essex
}

\begin{abstract}
Guberan, E., Williams, M. K., Walford, Joan, and Smith, Margaret M. (1969). Brit. J. industr. Med., 26, 121-125. Circadian variation of F.E.V. in shift workers. The one-second forced expiratory volume $($ F.E.V.1.0), the forced vital capacity, and the oral temperature were measured in a group of men working a rotating three-shift system -2 to $10 \mathrm{p} . \mathrm{m}$. one week, 10 p.m. to 6 a.m. the next week, and 6 a.m. to 2 p.m. the third week. The outside air temperature at the London Weather Centre was also obtained. Measurements were made on Mondays and Fridays at the beginning, middle, and end of the shift.

The mean F.E.V.1.0 19 normal men showed an increase of 0.15 litre $(4.1 \%)$ between the beginning and end of both the morning shifts, a mean decrease of some 0.05 litre $(1.5 \%)$ between the beginning and end of the afternoon shifts, and little change during the night shifts. This circadian variation could not be attributed to industrial fume, smoking or a learning effect.

The findings will be of practical importance when F.E.V. is measured in shift workers to determine the effects of toxic substances on ventilatory capacity.
\end{abstract}

Previous studies indicate that there is a circadian variation of ventilatory capacity (Lewinsohn, Capel, and Smart, 1960; McDermott, 1966; McKerrow, McDermott, Gilson, and Schilling, 1958; Bouhuys, Hartogensis, and Korfage, 1963; Walford, Lammers, Schilling, van den Hoven van Genderen, and van der Veen, 1966). A survey of the forced expiratory volume of a group of men working a rotating three-shift system has been made in order to obtain more precise information. Oral temperature was also measured to determine whether there is an association between the circadian variation of oral temperature (e.g., Kleitman, 1963) and the forced expiratory volume.

\section{Material and methods}

The survey was carried out in a factory making plastic 1Present address: Service Cantonal de Médecine du Travail et d'Hygiene Industrielle, Hôpital de la Chaux-de-Fonds, Switzerland. boxes and separators for car batteries. Men were sought who worked a rotating three-shift system, 2 to 10 p.m. one week, 10 p.m. to 6 a.m. the next week, and 6 a.m. to 2 p.m. the third week, and so on. Of the three groups available, one, comprising 27 men, was asked to take part. Every man agreed, but one man was excluded because he was going on holiday. Measurements were made, during August, on Mondays and Fridays for three consecutive weeks starting when the men were on the 2 to 10 p.m. shift. The men's mean age was 33, with a range of 21 to 59 years, and mean height $5 \mathrm{ft}$. 9 in. $(174 \mathrm{~cm}$.), with a range of $5 \mathrm{ft} .3 \mathrm{in} .(160 \mathrm{~cm}$.) to $6 \mathrm{ft} .5 \mathrm{in}$. $(196 \mathrm{~cm}$.). All the men were Caucasians.

Some of the men were exposed to isophorone and white spirit vapour, others to a little molten pitch fume, and others to a hot humid environment. The physical exertion required for the jobs varied between moderate and heavy.

The Short Questionnaire on Respiratory Symptoms approved by the Medical Research Council's Committee on the Aetiology of Chronic Bronchitis (1960) was completed at an interview with each man, and chest 
radiographs were arranged for all men who had not been $x$-rayed during the previous 12 months.

Measurements of the one-second forced expiratory volume (F.E.V.1.0), the forced vital capacity (F.V.C.) and oral temperature were made before the men started work, in the middle of the shift before the meal break, and at the end of each shift. F.E.V.1.0 and F.V.C. were determined with two Gaensler-type spirometers (McKerrow, McDermott, and Gilson, 1960) by two observers (E.G. and M.K.W.). Each observer used the same instrument and measured the same men throughout the survey. On every occasion four blows were made and readings of F.E.V.1.0 were recorded. The third and fourth blows were prolonged and F.V.C. readings were also taken. F.E.V.1.0 was calculated as the mean of the last three readings and F.V.C. as the mean of the two readings. The men had obtained practice in an initial experiment designed to compare the two observerinstrument combinations.

Each instrument was calibrated by adjusting the timer until the mean of four readings obtained with the weight and standard orifice was within $\mathbf{0 . 2}$ litre of the maker's standard, and was checked at least every 15 minutes. The water temperature was maintained at $22 \cdot 0 \pm 1.0^{\circ} \mathrm{C}$. with hot water or ice. Each subject sat for not less than 5 minutes before each test, and the oral temperature was taken. During each set of observations the air temperature near the instruments was measured. The outside air temperature at the London Weather Centre, within 15 miles of the factory, was obtained subsequently.

\section{Results}

Of the 26 men who entered the survey, one man missed three of the six shifts for domestic reasons and his results were excluded. Of the remaining 25 men, six were considered to be abnormal for one or more of the following reasons: phlegm on most days for three months each year (question 10 of the M.R.C. approved questionnaire); F.E.V.1.0, F.V.C., or $\frac{\text { F.E.V.1.0 }}{\text { F.V.C. }}$ less than $80 \%$ of the 'average normal' value predicted from height and age (Cotes, Rossiter, Higgins, and Gilson, 1966). Two of these six men each missed one work-period. Of the remaining 19 'normal' men, none missed a work-period.
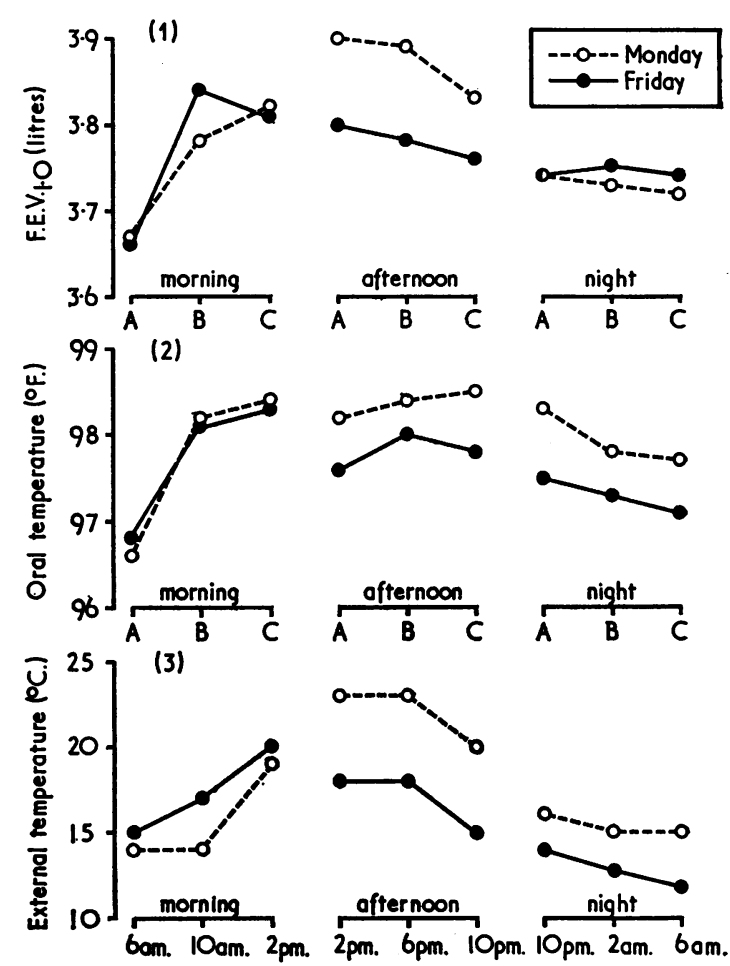

FIGURE (1) Mean F.E.V.1.0, and (2) mean oral temperature of 19 normal men at the beginning (A), in the middle (B), and at the end (C) of morning, afternoon, and night shifts on Mondays and Fridays. (3) External air temperature at corresponding times.

TABLE 1

Mean F.E.V.1.0 AND F.V.C. Of 19 Normal Men at the Beginning, In the Middle, and at the End OF EACH SHIFT

\begin{tabular}{c|c|c|c|c|c|c|c}
\hline \multirow{2}{*}{ Shift } & \multirow{2}{*}{ Day } & \multicolumn{3}{c|}{ F.E.V.1.0 (litres) } & \multicolumn{3}{c}{ F.V.C. (litres) } \\
\cline { 3 - 7 } & & Beginning & Middle & End & Beginning & Middle & End \\
\hline Morning (6 a.m.-2 p.m.) & Monday & 3.67 & 3.78 & 3.82 & 5.00 & 5.05 & 5.06 \\
& Friday & 3.66 & 3.84 & 3.81 & 5.01 & $5 \cdot 14$ & 5.07 \\
Afternoon (2 p.m.-10 p.m.) & Monday & 3.90 & 3.89 & 3.83 & 5.14 & 5.15 & 5.10 \\
& Friday & 3.80 & 3.78 & 3.76 & 5.07 & 5.08 & 5.00 \\
Night (10 p.m.-6 a.m.) & Monday & 3.74 & 3.73 & 3.72 & 5.06 & 5.02 & 5.01 \\
& Friday & 3.74 & 3.75 & 3.74 & 5.04 & 5.04 & 5.03 \\
\hline
\end{tabular}


F.E.V.1.0 of normal men

Table 1 and the Figure show the mean F.E.V.1.0 of the 19 normal men at the beginning, in the middle, and at the end of each shift.

Morning shifts There was an increase of mean F.E.V.1.0 between the beginning and end of the morning shifts on both Monday and Friday of $0 \cdot 15$ litre $(4 \cdot 1 \%)$. The regressions of mean F.E.V.1.0 on the time at the beginning, middle, and end of the shift on each day differed significantly from zero $(P<0.001)$ and also from each other $(P<0.05)$, the mean F.E.V. on Friday showing a non-linear trend.

Afternoon shifts There were decreases in the mean F.E.V.1.0 between the beginning and end of the afternoon shifts on Monday of 0.07 litre $(1.8 \%)$ and on Friday of 0.04 litre $(1.1 \%)$. The regression slopes on each day were not significantly different from each other; the common slope, fitted to the pooled data, was significantly different from zero $(P<0.05)$. There was also a significant difference in the mean level $(P<0.001)$ between Monday and Friday.

Night shifts There was no statistically significant difference between the regression slopes on each day, and the common slope was not significantly different from zero. There was no statistically significant difference in the mean level of F.E.V.1.0.

Differences between shifts Differences in the regression slope between the morning and afternoon shifts, and between the morning and night shifts, on both Mondays and Fridays, were significant $(P<0.001)$. Differences in the slope between afternoon and night shifts were not significant.

Smoking Of the normal men, 15 were present smokers, one was a past smoker, and three were

TABLE 2

Median Time between the Last Smoke and Testing of 15 Normal Men SMOKers at the BeginNing, IN THE MidDle, AND AT THE END OF EACH SHIFT

\begin{tabular}{|c|c|c|c|c|}
\hline \multirow{2}{*}{ Shift } & \multirow{2}{*}{ Day } & \multicolumn{3}{|c|}{ Median time (min.) } \\
\hline & & Beginning & Middle & End \\
\hline $\begin{array}{l}\text { Morning } \\
\text { (6 a.m.-2 p.m.) }\end{array}$ & $\begin{array}{l}\text { Monday } \\
\text { Friday }\end{array}$ & $\begin{array}{l}40 \\
38\end{array}$ & $\begin{array}{l}80 \\
70\end{array}$ & $\begin{array}{l}60 \\
53\end{array}$ \\
\hline $\begin{array}{l}\text { Afternoon } \\
\text { (2 p.m.-10 p.m.) }\end{array}$ & $\begin{array}{l}\text { Monday } \\
\text { Friday }\end{array}$ & $\begin{array}{l}37 \\
38\end{array}$ & $\begin{array}{l}65 \\
65\end{array}$ & $\begin{array}{l}55 \\
49\end{array}$ \\
\hline $\begin{array}{l}\text { Night } \\
\text { (10 p.m. }-6 \text { a.m.) }\end{array}$ & $\begin{array}{l}\text { Monday } \\
\text { Friday }\end{array}$ & $\begin{array}{l}43 \\
40\end{array}$ & $\begin{array}{l}70 \\
61 .\end{array}$ & $\begin{array}{l}52 \\
50\end{array}$ \\
\hline
\end{tabular}

non-smokers. The minimum time for any of these 15 smokers between smoking and being tested was 10 minutes. The median time between smoking and being tested of the 15 smokers (Table 2) varied between 37 minutes and 80 minutes, and did not appear to be associated with the changes described. (The median time was used because the mean time was unduly influenced by a few extreme values.) The three non-smokers and the four heavy smokers among the normal men showed increases in mean F.E.V.1.0 between the beginning and end of the morning shifts of 0.10 litre $(2.5 \%)$ and 0.14 litre $(3.6 \%)$ respectively, decreases in mean F.E.V. between the beginning and end of the afternoon shifts of 0.02 litre $(0.5 \%)$ and 0.04 litre $(1.2 \%)$ respectively, and between the beginning and end of the night shifts an increase of 0.01 litre $(0.2 \%)$ and a decrease of 0.07 litre $(1.8 \%)$ respectively.

Sleep The mean time of last waking before both the morning shifts was about 4.45 a.m. (1 hour before blowing), before both the afternoon shifts it was

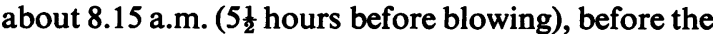

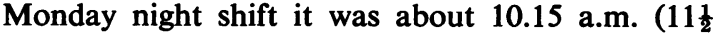
hours), and before the Friday night shift it was about 3.0 p.m. (63 hours). The difference in time of waking between the night shifts did not appear to influence the F.E.V.1.0.

Fume and heat Exposure to fume or a hot humid environment did not appear to affect the results. The mean F.E.V.s of the four men exposed to molten pitch fume, the three men most exposed to isophorone and white spirit vapour, and the four men exposed to a hot humid environment all showed similar changes.

\section{F.E.V.1.0 of abnormal men}

The mean F.E.V.1.0 of the six abnormal men

TABLE 3

Mean F.E.V.1.0 OF Six 'Abnormal' Men at THE BEGINNING, IN THE MIDDLE, AND AT THE END OF EACH SHIFT

\begin{tabular}{l|l|c|c|c}
\hline \multirow{2}{*}{ Shift } & \multirow{2}{*}{ Day } & \multicolumn{3}{|c}{ F.E.V.1.0 (litres) } \\
\cline { 3 - 5 } & & Beginning & Middle & End \\
\hline Morning & Monday & $2 \cdot 88$ & $3 \cdot 15$ & 3.07 \\
(6 a.m.-2 p.m.) & Friday & $2 \cdot 89$ & $3 \cdot 14$ & $3 \cdot 12$ \\
Afternoon & Monday & $2 \cdot 68^{1}$ & $2 \cdot 72^{1}$ & $2 \cdot 63^{1}$ \\
(2 p.m.-10 p.m.) & Friday & $3 \cdot 11$ & $3 \cdot 16$ & 3.09 \\
& & & & \\
Night & Monday & $3 \cdot 13$ & 3.07 & 3.00 \\
(10 p.m.-6 a.m.) & Friday & 3.01 & 3.08 & 3.03 \\
\hline
\end{tabular}

${ }^{1}$ Two men absent. 
(Table 3) showed a similar pattern to that of the normal men, but the mean increase between the beginning and end of the two morning shifts, 0.21 litre $(7.3 \%)$, was greater than in the normal men.

\section{F.V.C. of normal and abnormal men}

The mean F.V.C. of the normal men (Table 1) varied in a similar manner to the mean F.E.V.1.0, showing a rise during the morning shifts, a fall during the afternoon shifts, and little change during the night shifts. But the increase in the mean F.V.C. between the beginning and end of the morning shifts on both Monday and Friday was only 0.06 litre $(1.2 \%)$ compared with the increase of 0.15 litre $(4.1 \%)$ in F.E.V.1.0. Changes in the mean F.V.C. of the abnormal men were similar.

\section{Oral temperature and air temperature}

The mean oral temperature of the 19 normal men (Figure) showed an increase of $1.8^{\circ} \mathrm{F}$. and $1.5^{\circ} \mathrm{F}$. between the beginning and end of the morning shift on Monday and Friday respectively. There were small increases of $0.3^{\circ} \mathrm{F}$. and $0.2^{\circ} \mathrm{F}$. between the beginning and end of the afternoon shifts, and small decreases of $0.6^{\circ} \mathrm{F}$. and $0.4^{\circ} \mathrm{F}$. between the beginning and end of the night shifts. The mean oral temperature was about $0.5^{\circ} \mathrm{F}$. lower on Fridays than on Mondays during both the afternoon and night shifts. The size and phase of the circadian variation of oral temperature observed in these workers over three eight-hour shifts were similar to the findings in normal subjects throughout 24 hours (e.g., Kleitman, 1963).

There was some positive association between the mean F.E.V $\cdot_{1 \cdot 0}$ and mean oral temperature on the morning and night shifts, but on the afternoon shifts the association tended to be negative; there appeared to be a more consistent association between the mean F.E.V.1.0 and the outside air temperature (Figure). The temperatures where the men worked varied widely and were not measured.

\section{Discussion}

The results show a circadian variation of F.E.V.1.0 in these shift workers. Since there was an initial experiment to compare observer-instrument combinations, and the survey started with the afternoon shift, the increase in F.E.V. during the morning shifts cannot be attributed to a learning effect. Nor can the circadian variation be attributed to the effect of fume, a hot environment or smoking; men exposed and not exposed to fume and a hot environment were found to give similar patterns, and so were smokers and non-smokers. No obvious change was observed in the patterns between Monday and Friday.

The differences in the mean level of F.E.V.1.0 the Monday and Friday afternoon shifts $(0.088$ litre) were similar $(0.085$ and 0.091 litre $)$ in both observer-instrument combinations. The outside air temperature was the only known environmental difference. It was $5^{\circ} \mathrm{C}$. higher on the Monday afternoon shift than on the Friday afternoon shift, and there was an association between the F.E.V.1.0 and outside air temperature during the survey.

The circadian variation of F.E.V. observed in these shift workers is consistent with previous findings. McKerrow and his colleagues (1958) found a rise of $3.8 \%$ in F.E.V. 0.75 between 7 a.m. and 2 p.m. in 33 coal miners. Bouhuys and his colleagues (1963), studying the F.E. $\cdot_{\cdot 0 \cdot 75}$ in 16 flax workers, found a rise during the morning shift and a fall during the afternoon shift. It is of interest that in the present survey the abnormal men showed a larger increase during the morning shift than the normal men. Lewinsohn and his colleagues (1960) found an increase in F.E.V.1.0 $2.9 \%$ between 6 a.m. and 8 a.m. in five healthy men, and a much larger increase (36 to $60 \%$ ) in patients with obstructive airways disease; F.V.C. changes were similar. Walford and her co-workers (1966), studying the F.E. $V_{\cdot 0 \cdot 75}$ in shift workers in cotton mills, found in three separate groups of workers a mean increase during the morning shift and mean decreases during the afternoon and night shifts. The increase during the morning shift was more marked among workers with persistent cough and phlegm.

The present study indicates that shift workers without evidence of pulmonary disease may show an increase of some $0 \cdot 15$ litre in F.E.V.1.0 during the morning shift and a fall of some 0.05 litre in F.E.V.1.0 during the afternoon shift.

These findings will be of practical importance when determining the acute and chronic effects of toxic substances on ventilatory capacity in shift workers.

We are grateful to the men who took part in the survey, to Miss Rosemary Wood for computing assistance, and to Mrs. Ruby J. Cameron, R.C.N., for technical assistance.

We are also grateful to Professor Schilling for suggesting this investigation and to Dr. D. Malcolm and the Directors of Electric Power Storage Co., Ltd. for permission to undertake it at their factory.

\section{References}

Bouhuys, A., Hartogensis, F., and Korfage, H. J. H. (1963). Byssinosis prevalence and flax processing. Brit. J. industr. Med., 20, 320-323.

Cotes, J. E., Rossiter, C. E., Higgins, I. T. T., and Gilson, J. C. (1966). Average normal values for the forced expiratory volume in white Caucasian males. Brit. med. J., 1, 1016-1019.

Kleitman, N. (1963). Sleep and Wakefulness, 2nd ed. University of Chicago Press, Chicago and London.

Lewinsohn, H. C., Capel, L. H., and Smart, J. (1960). Changes in forced expiratory volumes throughout the day. Brit. med. J., 1, 462-464.

McDermott, M. (personal communication) cited by Mills, J. N. (1966). Human circadian rhythms. Physiol. Rev., 46, 128-171. 
McKerrow, C. B., McDermott, M., and Gilson, J. C. (1960). A spirometer for measuring the forced expiratory volume with a simple calibrating device. Lancet, 1, 149-151.

- and Schilling, R. S. F. (1958). Respiratory function during the day in cotton workers: a study in byssinosis. Brit. $J$. industr. Med., 15, 75-83.

Medical Research Council's Committee on the Aetiology of Chronic
Bronchitis (1960). Standardized questionnaires on respiratory symptoms. Brit. med. J., 2, 1665.

Walford, J., Lammers, B., Schilling, R. S. F., van den Hoven van Genderen, D., and van der Veen, Y. G. (1966). Diurnal variation in ventilatory capacity. An epidemiological study of cotton and other factory workers employed on shift work. Brit. J. industr. Med., 23, 142-148.

Received for publication August 9, 1968.

Reprint requests should be sent to Dr. M. K. Williams at the London School of Hygiene. 